\title{
Morfolojik Görüntü İșleme Tekniği ile Yapay Sinir Ağlarında Görüntü Tahribat Analizi
}

\author{
${ }^{* 1}$ Gökhan Atal1, ${ }^{2}$ S.Serdar Özkan, ${ }^{2}$ Durmuş Karayel \\ ${ }^{* 1}$ Sakarya Meslek Yüksekokulu, Mekatronik Programı Sakarya Üniversitesi, Türkiye \\ ${ }^{2}$ Teknoloji Fakültesi, Mekatronik Mühendisliği Sakarya Üniversitesi, Türkiye
}

Geliş Tarihi: 2015-12-25 Kabul Tarihi: 2016-04-09

\begin{abstract}
Öz
Teknolojinin gelişmesine paralel olarak kamera sistemlerinde yüksek düzeyde kaliteyi öngören lensler tasarlanmıştır. Ancak bu lensler yapısal olarak her ne kadar görüntü kalitesinde başarılı olsalar da üzerinde tahribat meydana gelmiş görüntülerin ayırt edilmesinde herhangi bir ek özellik mevcut değildir. Esasen bu tür tahribatların giderilmesi için yapay zeka teknikleri kullanmak mümkündür. Bu çalışmada, yapay sinir ağları kullanarak üzerinde tahribat meydana gelmiş görüntülerin morfolojik görüntü işleme teknikleri ile birleştirilerek tahribatın derecesine göre orijinal görüntüye yakınsaması ele alınmıştır. Ayrıca bu amaca ulaşmak ve kullanımı kolaylaştırmak amacıyla geliştirilen arayüz sayesinde eğitim ve test verilerinin yanı sıra ağı oluşturmak için kullanılacak parametrelerin kolaylıkla hazırlanan algoritmaya entegrasyonu sağlanmaktadır.
\end{abstract}

Anahtar Kelimeler: Yapay Sinir Ağları, Karakter Tespiti, Morfolojik Görüntü İşleme

\section{Image Damage Analysis With Morphological Image Processing Technique Using Artificial Neural Networks}

\author{
${ }^{* 1}$ Gökhan Atall, ${ }^{2}$ S.Serdar Özkan, ${ }^{2}$ Durmuş Karayel \\ ${ }^{1}$ Sakarya Meslek Yüksekokulu, Mekatronik Programı Sakarya Üniversitesi, Türkiye \\ ${ }^{2}$ Teknoloji Fakültesi, Mekatronik Mühendisliği Sakarya Üniversitesi, Türkiye
}

\begin{abstract}
The lenses providing high quality for camera systems are designed as parallel with developing technologies. These lenses do not have any additional functionality to distinguish damaged images while they are successful with regard to image quality. Essentially, artificial intelligence techniques can be used to eliminate such damaged cases. In this study, convergence to original image of the damaged images according to the degree of damage using together artificial neural networks and morphological image processing techniques are discussed. Also, it is provided to be integrated training and test data with used algorithm thanks to developed interfaces to achieve goal and to facilitate use. In addition, this interface is used to be entered the training parameters to the system.
\end{abstract}

Keywords: Artificial Neural Networks (ANN), Character detection, Morphological image processing

\section{Giriş}

Günümüzde birçok alanda morfolojik görüntü işleme teknikleri ile çeşitli analizler yapılmaktadır. Bunlardan en bilinenleri; araç plakası tanıma, bant üzerindeki ürünlerin tanımlanması, cisimlerin çap ve boy uzunlukları için görüntü analizleridir. Görüntü işleme esasen görüntünün sayısallaştırılarak veri setlerine dönüştürülmesi ve çeşitli yöntemlerle işlenmesi olarak tanımlanır. Bu konu ile ilgili yapılan çalışmalar incelendiğinde araştırmacıların; kenar ayrıştırma, Hough dönüşümü, simetri özelliği, renk özelliği, histogram analizi, Gabor süzgeçleri gibi görüntü işleme tekniklerini kullandıkları görülmektedir [1-8].

*Corresponding author: Address: Sakarya Meslek Yüksekokulu, Mekatronik Programı Sakarya Üniversitesi, 54187, Sakarya TÜRKIYE. E-mail address: gatali@ sakarya.edu.tr, Telefon: +902642953495 
$\mathrm{Bu}$ konu hakkında Literatür incelendiğinde; Fatih Kahraman ve arkadaşları aktif görünüm modeline dayalı yüz tanıma isimli çalışmalarında insan yüzünün temel bileşenlerini otomatik olarak saptayan aktif görünüm modeline ve Gabor süzgeçlerine dayalı bir yüz tanıma yöntemi geliştirmişlerdir [9]. C.Tu ve arkadaşları Hough dönüşümünü kullanarak araçların belirli bir rota üzerindeki pozisyonlarının bulunmasını amaçlamış ve bu konuda bir çalışma gerçekleştirmişlerdir [10]. C. Lopez-Molina ve arkadaşları ayrıt saptama yöntemine ait performans analizleri üzerine çalışma yapmışlardır [11].

Görüntü üzerinde yer saptama için en yaygın olarak kullanılan yöntemlerin başında ayrıt saptama ve eşikleme tabanlı yöntemler gelmektedir. Ayrıt saptama ve eşikleme giriş görüntüsünü 1 ve 0 bilgilerinden oluşan ikili resme dönüştürmek için kullanılır. Daha sonra elde edilen bu ikili resmin dikey ve yatay izdüşüm histogramları analiz edilerek resmin üzerinde istenilen bölgeler tespit edilir [12-17]. Diğer bir yöntemde ayritlar bulunduktan sonra Hough dönüşümü uygulanarak resmin çevresi bulunmaktadır [18]. Bahsedilen bu yöntemler ile elde edilen ikili moda dönüştürülmüş sayısal görüntü üzerinde morfolojik açma ve kapama gibi işlemler uygulanarak görüntüyü gerçek halinden uzaklaştırmak mümkündür. Esasen burada gerçek görüntüden uzaklaşmadan maksat, görüntü üzerinde tahribat meydana geldiği manasındadır. Çevre şartlarından ve metnin yazılı olduğu zeminden kaynaklı problemler gibi birçok olumsuz etki görüntü üzerine yansımakta ve görüntüyü gerçek halinden uzaklaştırmaktadır.

$\mathrm{Bu}$ çalışmada bahsedilen bu etkilere benzer şekilde görüntü üzerinde morfolojik açma ve kapama işlemleri uygulanarak görüntü üzerinde tahribat meydana getirilmiştir. Üzerinde değişiklik meydana gelerek farklı bir görüntü haline gelen yeni görüntü, tahribat analizi yaparak doğruya yaklaşımda bulunan bir yapay sinir ağına (YSA) test verisi olarak sunulmuş ve analiz edilmiştir. $\mathrm{Bu}$ işlemler sırasında eğitim verileri için hazırlanan resimler üzerinde ayrıt saptama, eşikleme yöntemleri kullanılmış ardından oluşan ikili bilginin dikey yatay izdüşümleri bir veri setine dönüştürülerek MATLAB ortamında yapay sinir ağları tarafindan oluşturulan bir ağa eğitim verisi olarak tanıtılmıştır. Ayrıca çalışmada MATLAB ortamında bir arayüz tasarlanarak veri setlerinin eğitimi ve testleri için uygulanacak fonksiyon çeşitleri, ara katman sayısı, ara katmandaki nöron sayısı, açma-kapama miktarı gibi bilgilerin dışarıdan müdahale ile değiştirilebilir olması sağlanmıştır.

\section{Yapay Sinir Ağları ve Görüntü İşleme}

Yapay Sinir Ağları (YSA), insan beyninin bilgi işleme tekniğinden esinlenerek geliştirilmiş bir bilgi işlem teknolojisidir. YSA ile basit biyolojik sinir sisteminin çalışma şekli simüle edilmektedir. Simüle edilen sinir hücreleri nöronlar içerirler ve bu nöronlar çeşitli şekillerde birbirlerine bağlanarak ağı oluştururlar. Bu ağlar öğrenme, hafizaya alma ve veriler arasındaki ilişkiyi ortaya çıkarma kapasitesine sahiptirler. Diğer bir ifadeyle, YSA'lar, normalde bir insanın düşünme ve gözlemlemeye yönelik doğal yeteneklerini gerektiren problemlere çözüm üretmektedir. Bir insanın, düşünme ve gözlemleme yeteneklerini gerektiren problemlere yönelik çözümler üretebilmesinin temel sebebi ise insan beyninin ve dolayısıyla insanın sahip olduğu yaşayarak veya deneyerek öğrenme yeteneğidir. Görüntü işleme ölçülmüş veya kaydedilmiş olan dijital görüntü verilerini, elektronik ortamda çeşitli yazılımlar ile amaca uygun şekilde değiştirmeye yönelik yapılan çalışmaları kapsamaktadır. Görüntü işleme, daha çok, kaydedilmiş olan, mevcut görüntüleri işlemek, yani mevcut resim ve grafikleri, değiştirmek, yabancılaştırmak ya da iyileştirmek için kullanılmaktadır.

\section{Morfolojik Görüntü İşleme}

Matematiksel morfoloji, lineer olmayan komşuluk işlemlerinde güçlü bir görüntü işleme analizidir. Morfolojik görüntü işlemede genişletme ve aşındırma isimli temel iki işlem kullanılmaktadır. Morfolojik görüntü işlemede bilinen açma ve kapama işlemleri gibi diğer tüm yöntemler bu iki işlemi referans alarak gerçekleştirilir. Üzerinde kare ve daire gibi geometrik şekillerle yapısal filtre uygulanan görüntü açma veya kapama gibi morfolojik işlemlere tabi tutulur. Ancak görüntü üzerinde yapısal filtre uygulayarak genişletme veya aşındırma işlemi yapabilmek için görüntü önce binary (ikili) moda çevrilir.

\subsection{Genişletme İşlemi}

İkili moda dönüştürülen görüntü üzerinde büyütme ya da kalınlaştırma işlemlerinin yapıldığı morfolojik işlemleri kapsamaktadır. Sayısal bir resmi genişletmek resmi yapısal elemanla kesiştiği bölümler kadar büyütmek demektir. Kalınlaştırma işleminin nasıl yapılacağını Şekil 3'te örnek verilen yapı elemanları belirler. Şekil 1 de görüldüğü üzere üzerinde genişletme yapılan sayısal görüntüde açma meydana gelmiş ve dolayısıyla görüntüde normalin dışına çıkan bir bozulma gözlenmektedir. 

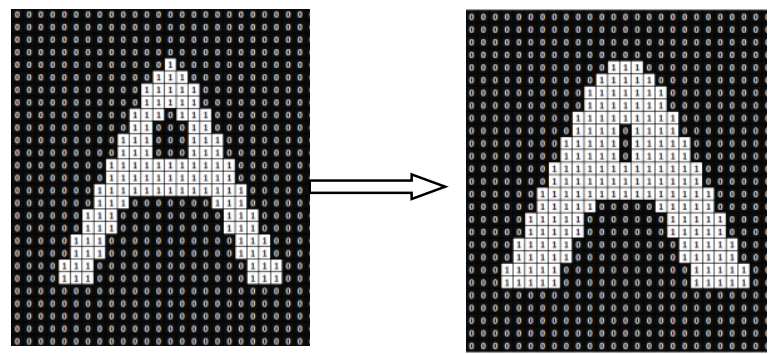

Şekil 1. 3x3 yapısal elemanı ile genişletme işlemi

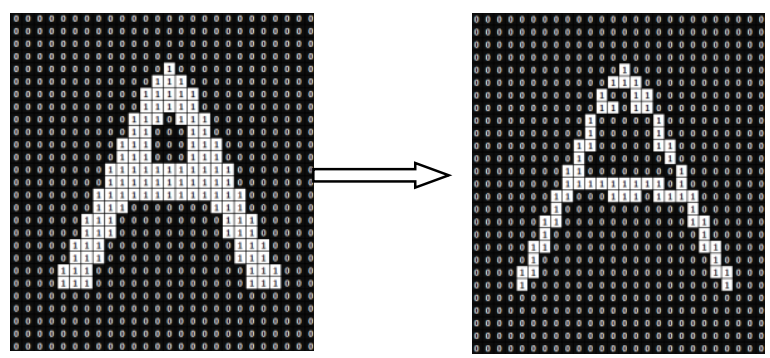

Şekil 2. 3x3 yapısal elemanı ile aşındırma işlemi

\subsection{Aşıిındırma İşlemi}

İkili moda dönüştürülen görüntü üzerinde küçültme ya da inceltme işlemlerinin yapıldı ğı morfolojik işlemleri kapsamaktadır. Aşındırma işlemi bir bakıma genişletme işleminin tersidir. Aşındırma işlemi ile sayısal resim üzerinde inceltme yapılmış dolayısıyla görüntüde tahribat meydana gelmiş olur. Aşındırmadan kaynaklı bu tahribat sonucunda resim içerisindeki nesneler boyutsal olarak daralır, delik varsa genişler ve bağlı nesneler ayrılma eğilimi gösterir. Şekil 2 de aşındırma işlemi için bir örnek görüntü verilmiştir.

Eğer sayısal bir görüntüye genişletme ve aşındırma işleminin ardışık olarak uygulanırsa görüntüde açma işlemi meydana gelmektedir. Açma işleminde birbirine yakın iki nesne görüntüde fazla değişime sebebiyet vermeden ayrılmış olurlar. Açmanın tersi olarak sayısal görüntü üzerinde aşındırma ve genişletme işleminin ardışık uygulanmasıyla da kapama işlemi meydana gelmektedir. Dolayısıyla birbirine yakın iki nesne görüntüde fazla değişiklik yapılmadan birbirine bağlanmış olur. $\mathrm{Bu}$ işlemlerin matematiksel gösterimi şu şekildedir;

$>$ Genişletme: $\mathrm{A} \square \mathrm{B}$

$>$ Aşındırma: A $\square \mathrm{B}$
$>$ Açma işlemi: $\mathrm{A}$ o $\mathrm{B}=(\mathrm{A} \square \mathrm{B}) \square \mathrm{B}$

$>$ Kapama işlemi: $\mathrm{A} \bullet \mathrm{B}=(\mathrm{A} \square \mathrm{B}) \square \square \mathrm{B}$

Yapısal eleman olarak adlandırılan ifade istenilen boyutlarda ve istenilen şekilde hazırlanmış matris formunda yapıları içermektedir. Yapısal eleman çeşitli geometrik şekillerden biri olabilmektedir; en sik kullanılan yapısal elemanlar kare, dikdörtgen ve daire şeklindedir. Yapısal eleman örnekleri Şekil 3' te gösterilmiş̧ir. Eğer morfolojik işlem olarak resimdeki nesnelerin keskin hatları silinip yerlerine kavisli veya daha yumuşak hatlar getirilmek isteniyorsa dairesel yapısal eleman kullanılmalıdır.

\begin{tabular}{|l|l|l|}
\hline 0 & 1 & 0 \\
\hline 1 & 1 & 1 \\
\hline 0 & 1 & 0 \\
\hline
\end{tabular}

\begin{tabular}{|l|l|l|}
\hline 0 & 1 & 1 \\
\hline 1 & 0 & 1 \\
\hline 1 & 1 & 0 \\
\hline
\end{tabular}

\begin{tabular}{|l|l|l|}
\hline 1 & 0 & 1 \\
\hline 0 & 1 & 0 \\
\hline 1 & 0 & 1 \\
\hline
\end{tabular}

Şekil 3. Yapısal eleman örnekleri

\section{Uygulama Çalış̧ması}

$\mathrm{Bu}$ çalı̧̧mada yapay sinir ağları ile üzerinde morfolojik görüntü işleme teknikleri uygulanmış sayısal görüntünün daha önceden ağa tanitılan orijinal resimler ile karşılaştırılması ve ağın doğruya yaklaşımları incelenmiştir. $\mathrm{Bu}$ yaklaşımları yapabilmek için Şekil 4'te verilen yol ve yöntemler sırası ile gerçekleştirilmiştir.

\section{1. Ĕ̈itim verilerinin alınması}

Geliştirilen bir ara yüz aracılığı ile ağda eğitime tabii tutulacak görüntülerin alınması bu basamakta gerçekleştirilmektedir. Ağda eğitilmesi düşünülen veri setleri $27 \times 27$ pixel boyutlarında (yaklaşık 18-24 punto) resimlerden oluşmaktadır. $\mathrm{Bu}$ resimler $50 \times 50$ boyutlarında sayısal 1 ve 0 değerlerinden oluşan sayısal veri seti haline getirildikten sonra 2500x1 sütun matrisine dönüştürülmektedir. $\mathrm{Bu}$ sayede görüntü yapay sinir ağlarında kullanılmak üzere hazır bir eğitim veri setine dönüştürülür. Veri seti olarak aşağıdaki gibi kullanılmıştır. Bu veri setlerinin \%20'si eğitim için, diğer \%80'i ise test için kullanılmıştır.

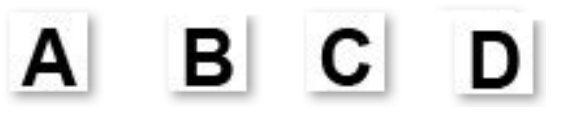




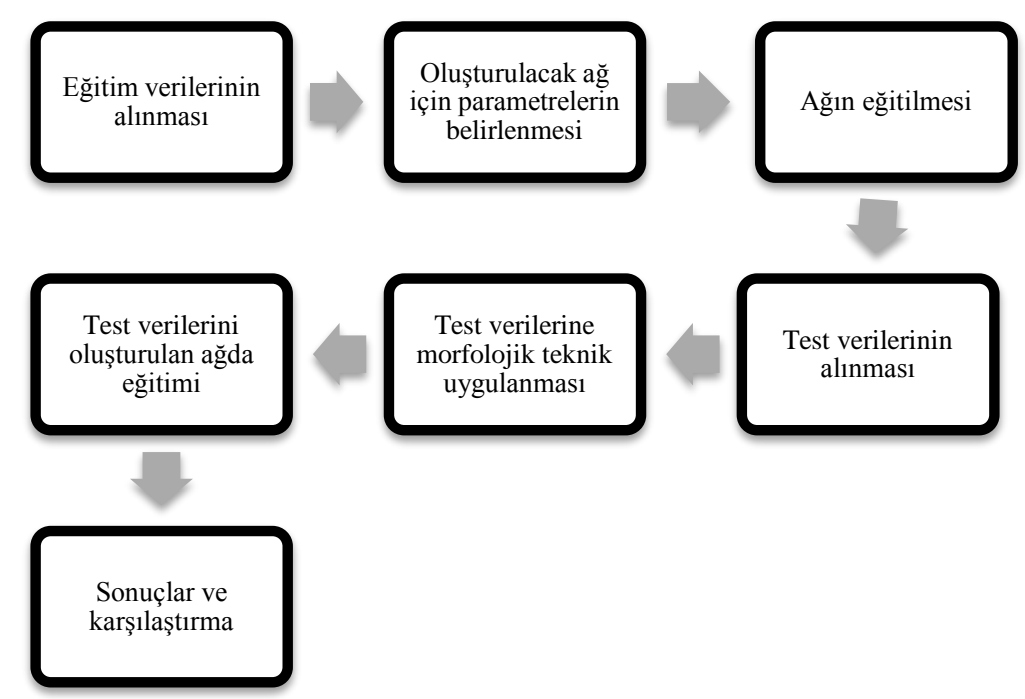

Şekil 4. Uygulamanın gerçekleşme basamakları

\subsection{Oluşturulacak ăg için parametrelerin belirlenmesi ve ă̆ın eğitimi}

Yapay sinir ağ oluşturmak için gerekli eğitim, performans ve transfer fonksiyonları ile ağda ulaşılması hedeflene nihai değer için gerekli parametrelerin girişi bu basamakta sağlanır. Ayrıca ilk katmandaki nöron sayısı ve maksimum epoch (devir) değeri de yine bu basamakta girilen parametreler arasında yer alır. Bu parametreler yapay sinir ağları oluşturulurken esas alınan temel parametrelerdir. $\mathrm{Bu}$ çalışmada izlenen yöntem ve teknikler için en uygun parametre dizisi Tablo 1 de verilmiştir.

Tablo 1 de belirtilen parametreler dahilinde ağa sunulan eğitim verilerinin eğitimi sonucu Şekil 5 ve Şekil 6 da görüldüğü üzere regresyon değeri 0.999 , gradyan değeri ise 148 iterasyonda 0.00010054 olarak saptanmıştır.

\subsection{Test verilerinin alınması ve morfolojik teknik uygulanmast}

Eğitilmiş ağda test etmek üzere test verilerinin alınması ve morfolojik teknik uygulayarak görüntü üzerinde tahribat meydana getirilmesi bu basamakta gerçekleştirilmiştir. Test verilerinin ağda eğitilmek üzere dosyadan alınması eğitim verileri için izlenen yöntem ve teknik ile aynıdır. Görüntüler sayısallaştırıldıktan sonra sayısal veri setine $1,2,3$ ve 4 derecelik dairesel ortalama filtresi ayrı ayrı uygulanmış ve görüntü orijinalliğinden uzaklaştırılarak, görüntüde tahribat meydana getirilmiştir (Şekil 7). Üzerinde değişiklik yapılan görüntü köşe bulma yöntemi ve ayrıt saptama tekniği ile uygun matris formuna dönüştürülmüş ve yapay sinir ağına test verisi olarak sunulmuştur. Daha sonra orijinal görüntü ile üzerinde tahribat meydana gelmiş görüntü metinsel ve görüntü olarak incelemeye tabii tutulmuş ve çıkarımda bulunulmuştur.

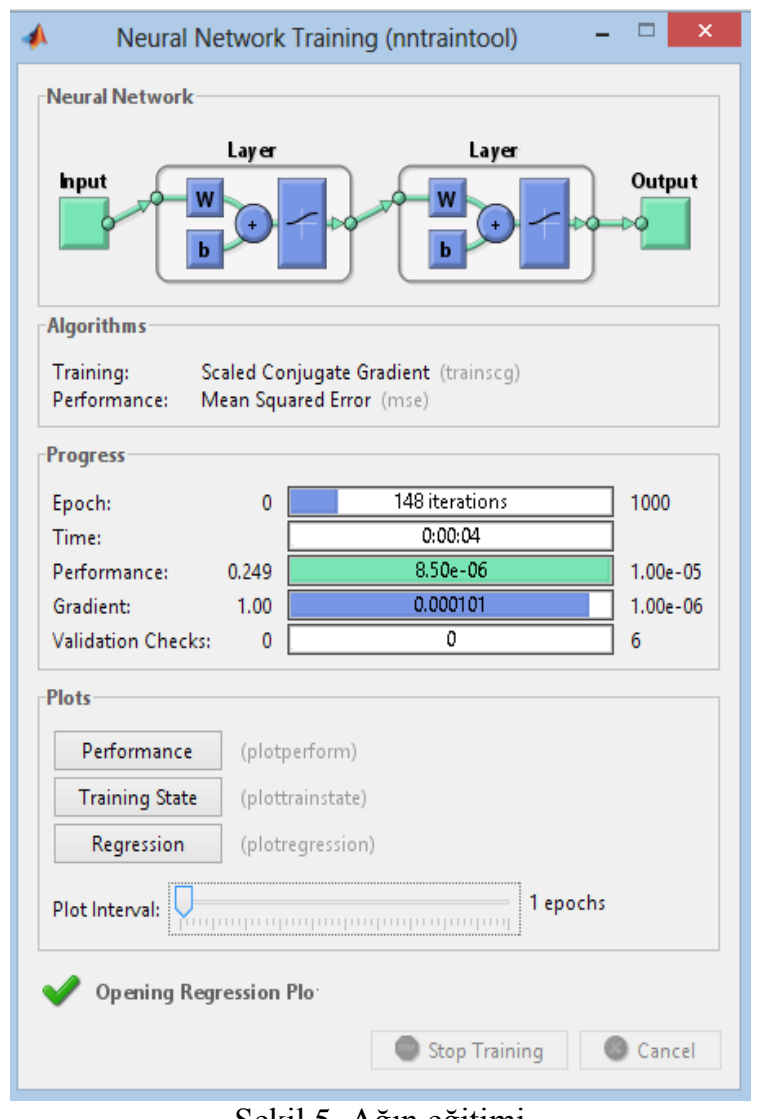

Şekil 5. Ağın eğitimi 

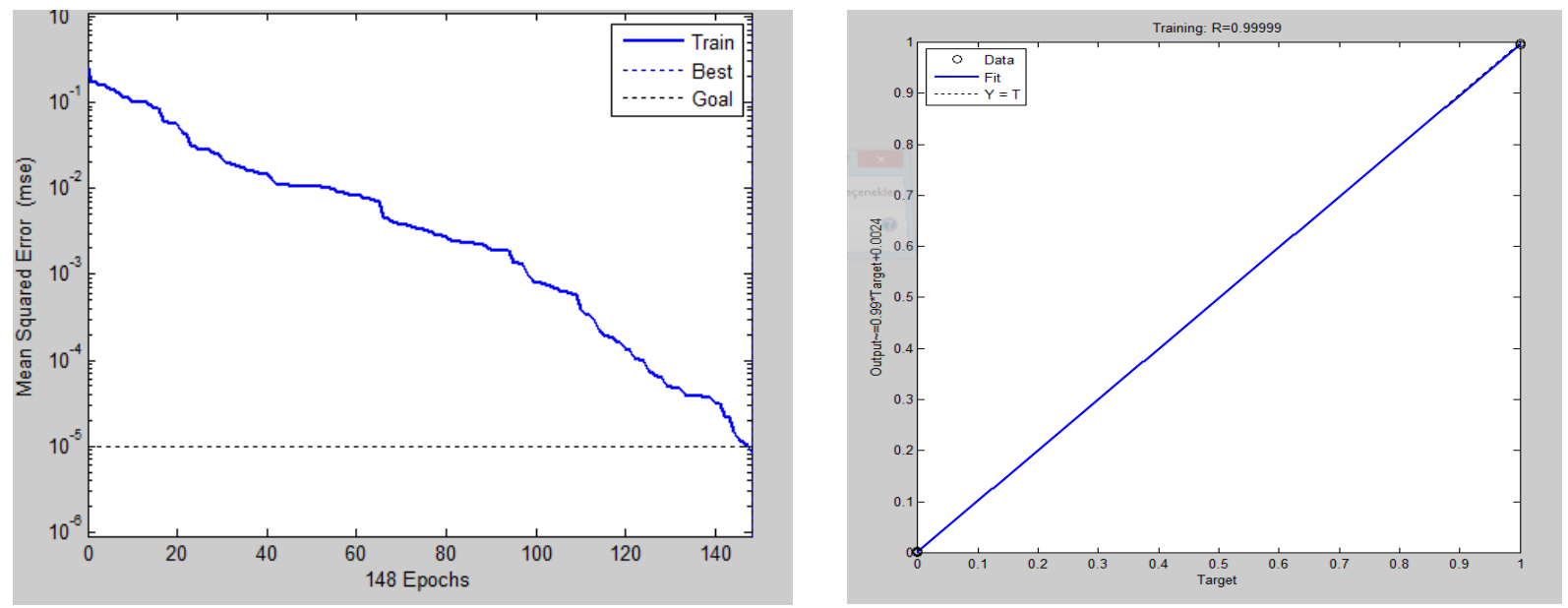

Şekil 6. Ağın eğitim sonuçları

Tablo 1. Belirlenen ağ parametreleri

\begin{tabular}{llllll}
\hline Eğitim fonk. & $\begin{array}{l}\text { Performans } \\
\text { fonksiyonu }\end{array}$ & Transfer fonk. & $\begin{array}{l}\text { Max. } \\
\text { Epoch }\end{array}$ & Hedef & $\begin{array}{l}\text { İlk katmandaki nöron } \\
\text { sayısı }\end{array}$ \\
\hline trainscg & mse & Logsig & 1000 & $1 \mathrm{e}-5$ & 10 \\
\hline
\end{tabular}

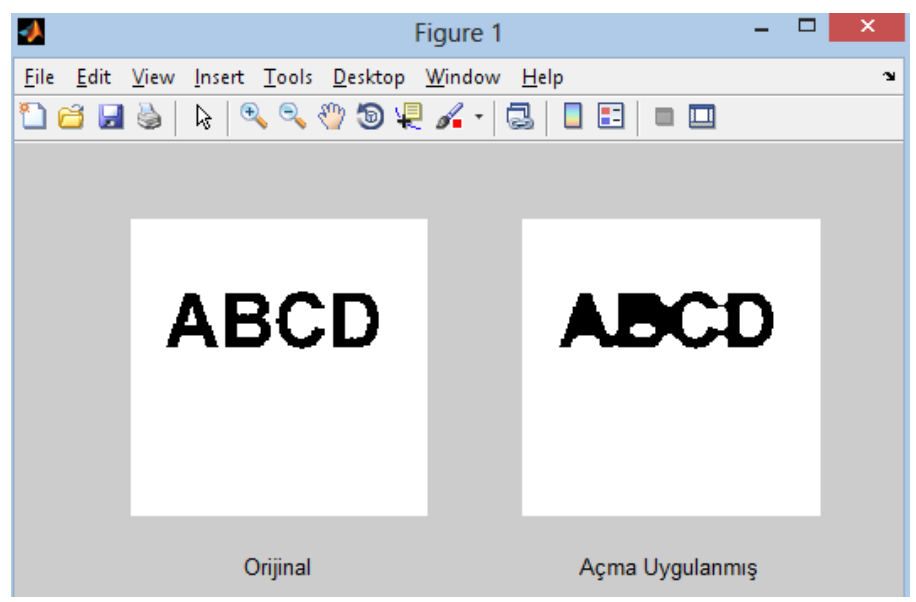

Şekil 7. 4 derecelik dairesel ortalama filtresi uygulanmış görüntü

\section{Sonuçlar ve Tartışma}

Görüntüler üzerinde çeşitli etkenlerden dolayı meydana gelen tahribatlar, morfolojik görüntü işleme platformundan yararlanılarak görüntü üzerinde oluşturulmuş ve yapay sinir ağları kullanılarak üzerinde tahribat meydana gelmiş görüntünün gerçeğe yakınlığı test edilmiştir. Görüntüde meydana gelebilecek bu tahribatlar dört farklı derecede dairesel ortalama filtresinin görüntüye uygulanması ile gerçekleşmiş ve sonuç olarak elde edilen değerler Tablo 2 ve Şekil 8'de sunulmuştur. Bu değerlere göre geliştirilen yapay sinir ağında, 2 ve 3 derecelik dairesel ortalama filtresi ile oluşturulan morfolojik görüntüde ortalama yüzde 75 başarım sağlanırken aşınma şayet 4 dereceye çıkarılırsa görüntünün orijinalliğinden oldukça uzaklaşması sebebiyle yaklaşımda da azalmanın görüldüğü sonucuna varılmıştır. Ayrıca tablo 2 de bahsi geçen yaklaşımlar var-yok olarak nitelendirilmiş ve bu doğrultuda yüzde olarak ifade edilmiştir. İlerleyen çalışmalarda yaklaşım değerleri fuzzy lojik ya da neuro fuzzy kullanılarak geniş aralıklarda ifade edilebilir. Meydana gelebilecek tahribatın Gaussian alçak geçiren filtresi, motion 
hareket benzetimi filtresi gibi değişik filtreler altında da incelenmesi sağlanabilir. Ayrıca bu çalışmadakine benzer uygulamaları içeren kamera lensleri tasarlanarak görüntülerin algı esnasında analizleri sağlanabilir.

Tablo 2. YSA yaklaşım karşılaştırmaları

\begin{tabular}{|c|c|c|c|c|c|c|c|}
\hline Test verisi & $\begin{array}{l}\begin{array}{l}\text { Morfolojik } \\
\text { sonuç }\end{array} \\
\end{array}$ & $\begin{array}{l}\text { Açma } \\
\text { Derecesi }\end{array}$ & Yaklaşım (\%) & Yaklaşım (\%) & $\begin{array}{l}\text { Açma } \\
\text { Derecesi }\end{array}$ & $\begin{array}{l}\text { Morfolojik } \\
\text { sonuç }\end{array}$ & \begin{tabular}{|l} 
Test \\
verisi
\end{tabular} \\
\hline A & A & 1 & 100 & 100 & 2 & $\mathrm{~A}$ & A \\
\hline $\mathrm{B}$ & $\mathrm{C}$ & 1 & 0 & 0 & 2 & $\mathrm{~A}$ & $\mathrm{~B}$ \\
\hline $\mathrm{C}$ & $\mathrm{C}$ & 1 & 100 & 0 & 2 & $\mathrm{D}$ & $\mathrm{C}$ \\
\hline $\mathrm{D}$ & $\mathrm{D}$ & 1 & 100 & 100 & 2 & $\mathrm{D}$ & $\mathrm{D}$ \\
\hline $\mathrm{AC}$ & $\mathrm{AC}$ & 1 & 100 & 100 & 2 & $\mathrm{AC}$ & $\mathrm{AC}$ \\
\hline $\mathrm{AD}$ & $\mathrm{AC}$ & 1 & 50 & 100 & 2 & $\mathrm{AD}$ & $\mathrm{AD}$ \\
\hline $\mathrm{ACB}$ & ACD & 1 & 66 & 100 & 2 & $\mathrm{ACB}$ & $\mathrm{ACB}$ \\
\hline $\mathrm{BAC}$ & $\mathrm{CAC}$ & 1 & 66 & 100 & 2 & $\mathrm{BAC}$ & BAC \\
\hline $\mathrm{CAB}$ & CAD & 1 & 66 & 66 & 2 & $\mathrm{CAC}$ & CAB \\
\hline CBA & CDA & 1 & 66 & 66 & 2 & $\mathrm{CCA}$ & CBA \\
\hline $\mathrm{ABCD}$ & ACCD & 1 & 50 & 75 & 2 & $\mathrm{ABCA}$ & $\mathrm{ABCD}$ \\
\hline \multicolumn{3}{|c|}{ Ortalama Yaklaşım: } & 69,455 & 73,364 & & & \\
\hline
\end{tabular}

\begin{tabular}{|l|l|l|l|l|l|l|l|}
\hline Test verisi & $\begin{array}{l}\text { Morfolojik } \\
\text { sonuç }\end{array}$ & $\begin{array}{l}\text { Açma } \\
\text { Derecesi }\end{array}$ & Yaklaşım (\%) & Yaklaşım (\%) & $\begin{array}{l}\text { Açma } \\
\text { Derecesi }\end{array}$ & $\begin{array}{l}\text { Morfolojik } \\
\text { sonuç }\end{array}$ & $\begin{array}{l}\text { Test } \\
\text { verisi }\end{array}$ \\
\hline A & A & 3 & 100 & 100 & 4 & A & A \\
\hline B & C & 3 & 0 & 0 & 4 & A & B \\
\hline C & C & 3 & 100 & 100 & 4 & C & C \\
\hline D & D & 3 & 100 & 0 & 4 & C & D \\
\hline AC & AC & 3 & 100 & 100 & 4 & AC & AC \\
\hline AD & AC & 3 & 50 & 50 & 4 & AC & AD \\
\hline ACB & ACA & 3 & 66 & 66 & 4 & ACC & ACB \\
\hline BAC & BAC & 3 & 100 & 66 & 4 & AAC & BAC \\
\hline CAB & CAB & 3 & 100 & 66 & 4 & CAD & CAB \\
\hline CBA & CBA & 3 & 100 & 66 & 4 & CDA & CBA \\
\hline ABCD & ACCD & 3 & 50 & 50 & 4 & ADCA & ABCD \\
\hline Ortalama Yaklaşım & & 78,727 & $\mathbf{6 0 , 3 6 4}$ & & & \\
\hline
\end{tabular}

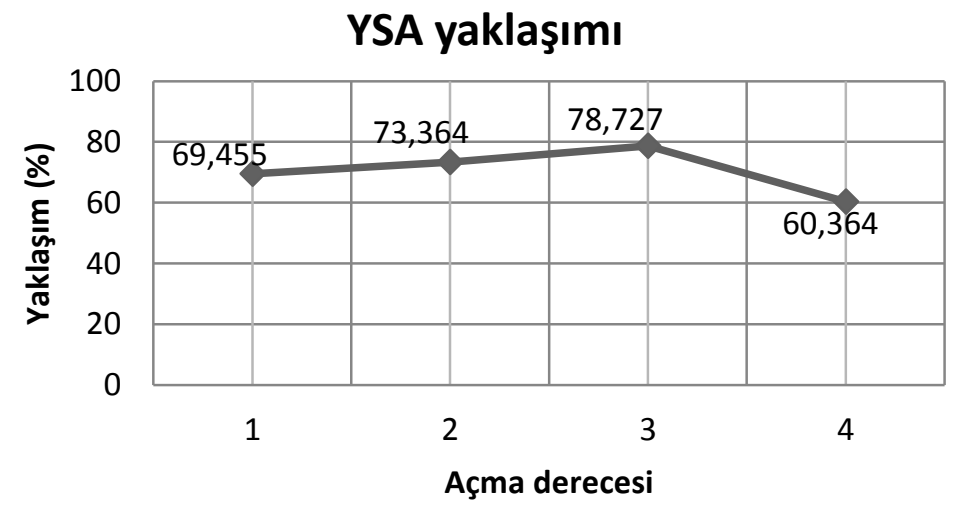

Şekil 8. 1-2-3-4 derecelik açma derecelerine karşı YSA yaklaşımı 


\section{Referanslar}

[1] Barroso, J., Rafael, A., Dagless, E. L., Bulas-Cruz, J., Number plate reading using computer vision, IEEE

- International Symposium on Industrial Electronics ISIE'97, Universidade do Minho, Guimarães, 1997.

[2] Morphological Segmentation for Textures and Particles, Published as Chapter 2 of Digital Image Processing Methods, E. Dougherty, Editor, MarcelDekker, New York, 1994, Pages 43--102.

[3] B. Hongliang and L. Changping. A hybrid license plate extraction method based on edge statistics and morphology.17th International Conference On Pattern Recognition(ICPR'04), 2:831-834, 2004.

[4] M. Sarfraz, M. J. Ahmed, and S. A. Ghazi. Saudi arabian license plate recognition system. Proceedings of the 2003 International Conference on Geometric Modeling and Graphics(GMAG'03), pages 36-41, 2003.

[5] V. Kamat and S. Ganesan. An efficient implementation of hough transform for detecting vehicle license plate using dsp's. 1st IEEE Real-Time Technology and Applications Symposium, pages 5859, 1995.

[6] V. Shapiro, D. Dimov, S. Bonchev, V. Velichkov, and G. Gluhchev. Adaptive license plate image extraction. International Conference on Computer Systems and Technologies, 2003.

[7] F. Mart'1n, M. Garc'ia, and J. L. Alba. New methods for automatic reading of vlps (vehicle license plates). Signal Processing Patten Recognition and Application, 2002.

[8] Kahraman F., Gökmen M. "GABOR Süzgeçler Kullanılarak Taşıt Plakalarının Yerinin Saptanması”, 11. sinyal İşleme ve İletişim Uygulamaları Kurultayı, İstanbul, 2003.

[9] F. Kahraman, B.Kurt, M.Gökmen "Aktif Görünüm Modeline Dayalı Yüz Tanıma" Signal Processing and Communications Applications Conference, 2005. Proceedings of the IEEE 13th, May 2005, Pages 483486, Print ISBN: 0-7803-9239-6.
[10] C.Tu, B.J van Wyk, Y. Hamam, K. Djouani, Shengzhi Du "Vehicle Position Monitoring Using Hough Transform" IERI Procedia Volume 4, 2013, Pages 316-322 2013 International Conference on Electronic Engineering and Computer Science (EECS 2013).

[11] C.Lopez-Molina, B. De Baets, H. Bustince "Quantitative error measures for edge detection" Pattern Recognition Volume 46, Issue 4, April 2013, Pages 1125-1139.

[12] P. Ponce, S. S. Wang, D. L. Wang, "License Plate Recognition-Final Report", Department of Electrical and Computer Engineering, Carnegie Mellon University, 2000.

[13] M. Yu and Y. D. Kim, “'An Approach to Korean License Plate Recognition Based on Vertical Edge Matching", IEEE International Conference, vol. 4, 2975-2980, 2000.

[14] J.R. Parker, P. Federl, “An Approach To Licence Plate Recognition", The Laboratory For Computer Vision, University of Calgary, 1996.

[15] Cui Y., Huang Q., Extracting Characters of License Plates from Video Sequences, Machine Vision and Applications 10, 308-320, 1998.

[16] Naito, T., Tsukada, T., Yamada, Yamamoto, S., Robust License-Plate Recognition Method for Passing Vehicles under Outside Environment, IEEE Trans. Vehicular Technology 49, 2309-2319, 2000.

[17] Nishiyama, K., Kato, K., Hinenoya, T.: Image processing system for traffic measurement, Proceedings of International Conference on Industrial Electronics, Control and Instrumentation Kobe, Japan, (1991) 1725-1729.

[18] Lu, Y., Machine printed character segmenation, Pattern Recognition, vol. 28, n. 1, 67-80, Elsevier Science Ltd, UK, 1995. 